\title{
PENERJEMAHAN DAN VALIDASI KUESIONER "EDUCATIONAL NEEDS OF CAREGIVERS INSTRUMENT" KE DALAM BAHASA INDONESIA PADA CAREGIVERS PASIEN GAGAL JANTUNG
}

\author{
Sri Rahayu ${ }^{*}$, Hsing-Mei Chen ${ }^{2}$ \\ ${ }^{1}$ Program Studi Ilmu Keperawatan, Sekolah Tinggi Ilmu Kesehatan Jayakarta \\ Jl. Raya PKP, Kel. Kelapa Dua Wetan, Kec. Ciracas, DKI Jakarta, Indonesia \\ Email: ${ }^{1}$ srirahayu1903@gmail.com \\ ${ }^{2}$ Department of Nursing, College of Medicine, National Cheng Kung University \\ NCKU 1 University Road, North District, Tainan City, Taiwan 70101 \\ Email: ${ }^{2}$ hsingmei@mail.ncku.edu.tw
}

Tanggal Submisi: 1 Januari 2020; Tanggal Penerimaan: 26 Mei 2020

\begin{abstract}
ABSTRAK
Sampai sejauh ini belum tersedia instrumen atau kuesioner untuk mengetahui kebutuhan pendidikan caregivers pasien gagal jantung di Indonesia. Tujuan dari penelitian ini adalah untuk menerjemahkan dan memvalidasi kuesioner versi Bahasa Inggris "Educational Needs of Caregivers Instrument" ke dalam versi Bahasa Indonesia. Proses penerjemahan dan adaptasi dilakukan berdasarkan lima tahapan pedoman penerjemahan dan adaptasi dari World Health Organization. Hasil penelitian menunjukkan bahwa terdapat 5 istilah berbeda antara dua budaya: "talk" vs "discuss", "to know the expected course of the disease process", "to receive information about how to go about making lifestyle changes", "to feel as if others have my welfare in mind", "to have help with finansial concerns". Enam ahli dalam bidang kardiovaskuler dilibatkan dalam penilaian validasi konten instrumen. Hasilnya menunjukkan bahwa indeks validasi konten adalah 0.93 untuk relevansi, 0.91 untuk keakuratan, 0.83 untuk kejelasan, dan 0.84 untuk kemudahan dipahami. Pada akhirnya, tercipta kuesioner versi Bahasa Indonesia yang disebut "Kuesioner Kebutuhan Pendidikan Caregivers" dan kuesioner ini dinyatakan valid.
\end{abstract}

Kata kunci: Caregivers, Kebutuhan pendidikan, Penerjemahan, Validasi.

ISSN 1979-7621 (Print). ISSN 2620-7761 (Online)

\begin{abstract}
No instruments or questionnaires were available to measure the educational needs of caregivers of patients with heart failure in Indonesia. The purpose of this study was to translate and validate the English version of the "Educational Needs of Caregivers Instrument" into the Bahasa Indonesia version. The translation and adaptation process was done based on the World Health Organization's 5-step of translation and adaptation guidelines. The results showed that five terms were different between the two cultures: "talk"
\end{abstract}


vs. "discuss", "to know the expected course of the disease process", "to receive information about how to go about making lifestyle changes", "to feel as if others have my welfare in mind", "to have help with financial concerns". Six experts whose specialty was cardiovascular care were invited to assess the content validity of the instrument. The results showed that the content validity index was 0.93 for relevance, 0.91 for ambiguity, 0.83 for clarity, and 0.84 for simplicity. Finally, an Indonesian version of the instrument called "Kuesioner Kebutuhan Pendidikan Caregivers" was produced and stated as a valid questionnaire.

Keywords: Caregivers, Educational needs, Translation, Validation

\section{PENDAHULUAN}

Instrumen atau kuesioner sangat lazim digunakan dalam dunia pendidikan dan penelitian. Menurut Kamus Besar Bahasa Indonesia (KBBI) pengertian dari instrumen adalah sebuah sarana yang digunakan oleh peneliti untuk mengumpulkan data penelitian (KBBI, 2019). Instrumen juga bisa diartikan sebagai seperangkat alat tes. Banyak penelitian menggunakan instrumen sebagai alat pengambilan data. Seringkali, penelitian juga diawali dengan penerjemahan kuesioner sebelum digunakan pada populasi yang sebenarnya (Anggreani et al., 2019; Delphi \& Rating, 2014; Muhammad, Shatri, Djoerban, \& Abdullah, 2017; Pulignano et al., 2010; Soares et al., 2017; Sousa \& Rojjanasrirat, 2011). Hal ini penting untuk dilakukan jika bahasa kuesioner yang akan dipakai berbeda dengan populasi yang akan dilibatkan.

Sampai saat ini, di Indonesia belum ada sebuah instrumen untuk mengidentifikasi kebutuhan pendidikan caregivers pasien gagal jantung. Padahal, peranan caregivers dari pasien gagal jantung sangatlah vital. Beberapa penelitian menunjukkan bukti yang signifikan bahwa caregivers yang dimaksud mayoritas adalah keluarga (Collins \& K Swartz, 2011; National Alliance for Caregiving, 2015; Rahayu, 2017; Swartz, K., \& Collins, 2019). Keberadaan keluarga ternyata mampu meningkatkan kepercayaan diri dalam perawatan (Tsai et al., 2015). Tanpa mereka sadari, mereka sebenarnya perlu menyiapkan strategi perawatan yang efektif untuk memenuhi kebutuhan yang spesifik dalam melakukan perawatan yang lebih baik pada pasien gagal jantung (Hwang et al., 2011).

Salah satunya adalah dengan memenuhi kebutuhan pendidikan caregivers pasien gagal jantung. Ini sangat bermanfaat dalam meningkatkan pengetahuan dan cara perawatan yang benar, serta dapat mengurangi rasa ketidakpastian akan kondisi pasien, stres, depresi, serta meningkatkan kualitas hidup (Collins \& K Swartz, 2011; Etemadifar, Shahriari, Farsani, \& Bahrami, 2014; Moser, Dracup, \& Marsden, 1993; Walden et al., 2001). Penelitian menunjukkan bahwa pasien gagal jantung seringkali mengalami gangguan kualitas tidur, sehingga perlu adanya cara perawatan yang baik untuk mengatasinya (Chen, $\mathrm{H}$. M., \& Clark, 2007; Chen et al., 2009). 
Maka dari itu, perawatan yang dilakukan oleh caregivers pasien gagal jantung menjadi tantangan tersendiri.

Untuk mengetahui kebutuhan pendidikan caregivers pasien gagal jantung, diperlukan instrumen klinis untuk mengidentifikasinya. Namun, belum ada instrumen yang dimaksud di Indonesia. Adapun yang ditemukan adalah instrumen dalam bahasa Inggris yang berjudul "Educational Needs of Caregivers Instrument" (Moser et al., 1993). Instrumen tersebut perlu diterjemahkan terlebih dahulu, adaptasi dengan budaya Indonesia, dan juga validasi konten dari penilaian para ahli. Maka, dapat disimpulkan bahwa tujuan dari penelitian ini adalah untuk menerjemahkan dan memvalidasi kuesioner versi Bahasa Inggris "Educational Needs of Caregivers Instrument" ke dalam Bahasa Indonesia.

\section{METODE PENELITIAN}

Penelitian ini dimulai dengan permohonan izin kepada penulis kuesioner yaitu Debra K. Moser, PhD, RN, FAAN untuk diterjemahkan ke Bahasa Indonesia. Permohonan izin dilakukan pada bulan Januari 2016. Setelah mendapat izin, kemudian dilanjutkan dengan proses penerjemahan. Kuesioner diterjemahkan oleh lembaga penerjemah tersumpah. Proses penerjemahan dilakukan mulai bulan Februari sampai Maret 2016.

Penelitian ini menggunakan lima langkah proses penerjemahan dan adaptasi menurut World Health Organization (WHO) (2016) Guideline. Adapun lima langkah proses penerjemahan terdiri dari: Tahap (1) forward translation, yaitu kuesioner bahasa Inggris diterjemahkan ke Bahasa Indonesia oleh penerjemah tersumpah. Tahap (2) expert panel dilakukan untuk menentukan persamaan persepsi dari hasil terjemahan Bahasa Indonesia. Tahap (3) back-translation yaitu kuesioner terjemahan Bahasa Indonesia yang sudah didiskusikan dengan beberapa ahli, kemudian diterjemahkan kembali ke Bahasa Inggris. Tahap (4) pre-testing and cognitive interviewing, yaitu uji coba kuesioner pada target populasi. Tahap (5) final version, yaitu menyimpulkan akhir kuesioner.

Instrumen yang akan diterjemahkah dalam penelitian ini adalah "Educational Needs of Caregivers Instrument" yang telah dikembangkan oleh Moser et al. (1993). Instrumen ini digunakan untuk mengukur informasi kesehatan spesifik, dukungan emosional, dukungan finansial, informasi fisik dan psikologis dalam memberikan perawatan pada pasien gagal jantung. Akan tetapi, instrumen ini tidak memiliki subscale atau domain. Kuesioner ini berisi 29 item pernyataan dengan skala Likert 4 mulai dari 0 yang artinya "tidak penting" sampai 3 yang artinya "sangat penting". Rentang skor antara 0-87. Semakin tinggi nilainya, maka semakin penting kebutuhan pendidikannya.

Setelah proses penerjemahan selesai, selanjutnya dilakukan validasi konten untuk menilai Content Validity Index (CVI). Penilaian CVI mengacu pada teori (Polit \& Beck, 2006) dengan menggunakan 4 skala Likert yaitu 1=tidak relevan, 2=sedikit relevan, 3=relevan, 4=sangat relevan. Untuk menghitung setiap item 
pernyataan atau yang disebut ItemContent Validity Index (I-CVI) dihitung dari jumlah penilaian 3 atau 4 oleh para ahli dibagi dengan jumlah ahli yang memberikan penilaian. Sedangkan untuk menghitung nilai Mean I-CVI dihitung dari jumlah total I-CVI dibagi dengan jumlah seluruh pernyataan. Content Validity Index for Scale (S-CVI) yaitu S-CVI Universal Agreement (S-CVI/UA) dihitung dari jumlah I-CVI yang lebih dari 0,78 (jika 6 ahli yang menilai) dibagi dengan jumlah seluruh pernyataan. S-CVI Average (S-CVI/Ave) dihitung berdasarkan proporsi relevan dari item pernyataan yang dinilai 3 atau 4 oleh para ahli dibagi dengan jumlah ahli yang memberikan penilaian (Polit \& Beck, 2006). Pada penelitian ini, ahli yang dilibatkan untuk memberikan penilaian (expert jugdement) kuesioner adalah berjumlah 6 orang ahli. Para ahli yang dilibatkan yaitu Professor dari Fakultas Ilmu Keperawatan Universitas Indonesia, Dosen Keperawatan Universitas Soedirman, Dosen Keperawatan Universitas Diponegoro, Perawat senior RS Harapan Kita dengan latar belakang pendidikan S3 Keperawatan, Perawat RSUP Dr. Kariadi Semarang, dan juga Dokter Spesialis Penyakit Jantung RSUP Dr. Kariadi Semarang. Proses expert judgement dilakukan pada bulan April-Mei 2016. Setelah penilaian dari para ahli terkumpul, kemudian diolah dan dihitung kesepakatan para ahli tersebut.

\section{HASIL DAN PEMBAHASAN}

\section{Hasil Proses Penerjemahan}

Pada tahap (1) forward translation, dilakukan oleh dua orang penerjemah profesional Bahasa
Inggris-Bahasa Indonesia (bilingual translators). Hasilnya terdapat 1 (satu) perbedaan terjemahan pada kata "talk" yang berarti "bicara" dan "discuss" yang berarti "diskusi". Untuk mencari solusi, dilakukanlah tahap (2) yaitu experts panel dengan melibatkan penerjemah, 2 orang mahasiswa $\mathrm{PhD}$ dan 1 orang mahasiswa Master of Science dalam bidang Keperawatan. Hasilnya adalah arti kata "talk" menurut budaya Indonesia adalah membicarakan sesuatu tanpa arti, sedangkan "discuss" adalah lebih kepada hal yang serius dan membicarakan sesuatu dengan arti, ada makna atau isi atau konten pembicaraan. Kata-kata ini digunakan pada pernyataan no 3, 14, 21, 27. Sehingga hasil terjemahannya disesuaikan dengan kalimat pada pernyataan tersebut.

Selanjutnya tahap (3) backtranslation, dengan melibatkan penerjemah yang berbeda dari tahap 1 . Hasilnya ditemukan 4 (empat) perbedaan terjemahan yaitu pada pernyataan no 4 dari pernyataan "to know the prediction of the patient disease processes" menjadi "to know the expected course of the disease process", pada pernyataan no 9 dari pertanyaan " to get the information about going through changes in lifestyle practices" menjadi "to receive information about how to go about making lifestyle changes", pada pertanyaan no 13 dari pernyataan "to experience the thought that someone else is concerned regarding my welfare" menjadi "to feel as if others have my welfare in mind", pada pernyataan no 19 dari pertanyaan "to receive support in regards to finansial worries/concerns menjadi "to have help with finansial concerns". Untuk 
menyelesaikan perbedaan ini, hasil backward translation ditanyakan kepada pencipta kuesioner ini yaitu Debra K. Moser, PhD., RN, FAAN. Jawabannya adalah diterima dan masih sesuai dengan konsep kuesioner.

Tahap (4) pre-testing and cognitive interviewing, yaitu uji coba pada target populasi. Pada penelitian ini, target populasinya adalah caregivers keluarga yang merawat pasien gagal jantung. Jumlah caregivers keluarga yang dilibatkan yaitu 3 orang caregivers keluarga dari pasien gagal jantung. Responden memberikan masukan pada pernyataan no 2 yang semula berbunyi "untuk mengetahui perkiraan akhir proses penyakit" berubah menjadi "untuk mengetahui perkembangan proses penyakit pasien". Selain itu juga, masukan pada pernyataan no 24 dari "untuk memiliki waktu menyendiri" menjadi "untuk memiliki waktu buat diri saya sendiri".

Tahap terakhir (4) final
version, menyempurnakan kuesioner. Kuesioner "Educational Needs of Caregivers Instrument" yang sudah diterjemahkan ke dalam Bahasa Indonesia diberi nama "Kuesioner Kebutuhan Pendidikan Caregivers". Kata "kuesioner" lebih tepat untuk digunakan dalam pemberian nama karena sesuai dengan konteks bahasa Indonesia yang disebutkan dalam KBBI (2019) yang memiliki arti sebagai alat penelitian yang berisi serangkaian pertanyaan untuk mendapatkan tanggapan dari responden. Semua langkah proses tersebut sangatlah penting. Penjelasan tentang kuesioner yang asli dan kuesioner versi Bahasa Indonesia ditampilkan pada Tabel 1.

\section{Hasil Validasi Konten}

Pada tabel 2 dijelaskan bahwa hasil indeks validasi konten menunjukkan 0,93 untuk relevansi dari hasil kesepakatan 6 orang experts. Sedangkan hasil S-CVI/UA adalah 0,86 dan S-CVI/Ave adalah 0,93.

Selain itu, pada penelitian ini juga dihitung nilai keakuratan, kejelasan, dan kemudahan dipahami. Hasilnya didapatkan nilai mean I-CVI 0,91 untuk keakuratan; 0,83 untuk kejelasan; dan 0,84 untuk kemudahan dipahami.

\section{Pembahasan Proses Penerjemahan}

Proses penerjemahan kuesioner "Educational Needs of Caregivers instrument" telah dilakukan pada penelitian ini melalui tahapan-tahapan penerjemahan dan adaptasi menurut World Health Organization (2016). Kuesioner ini belum pernah diketahui ada terjemahan sebelumnya ke dalam Bahasa Indonesia. Penerjemahan kuesioner tidak hanya sebatas menerjemahkan kusioner saja, akan tetapi juga perlu mempertimbangkan budaya.

Pernyataan tersebut didukung oleh penelitian lainnya (Anggreani et al., 2019; Soares et al., 2017). Kedua hal tersebut baik penerjemahan dan adaptasi budaya dilakukan dalam penelitian ini sampai didapat kesimpulan akhir kuesioner. Beberapa pernyataan yang terdapat perbedaan arti/makna diklarifikasi dan diberitahukan kepada penciptanya. Pencipta kuesioner menyatakan kuesioner bahasa Indonesia sesuai dengan konsep kuesioner asli. 


\section{Tabel 1. Kuesioner "Educational Needs of Caregivers Instrument” Asli dan Versi Bahasa Indonesia}

\begin{tabular}{lll}
\hline No & Kuesioner Asli & \multicolumn{1}{c}{ Kuesioner Versi Bahasa Indonesia } \\
\hline 1. & $\begin{array}{l}\text { To get certain facts related to the patient's } \\
\text { condition }\end{array}$ & Untuk mengetahui kebenaran kondisi pasien secara jelas
\end{tabular}

2. To get the explanation that is true and easy to Untuk mendapat penjelasan yang benar dan mudah dipahami understand

3. To discuss with the doctors or nurses regarding a certain problem that I or my family member might face

4. To know the prediction of the patient disease Untuk mengetahui perkembangan proses penyakit pasien processes

5. To get detailed explanation about care

6. To expect that my I family member will have a high quality of life

7. To get the information about what I have to do in emergency cases

8. To get the information about the prediction of the patient's physical condition

9. To get information about going through changes in lifestyle practices

10. To feel appreciated/valued by my family members

11. To get the information about lifestyle changes

12. To help patient undergo a lifestyle change

13. To experience the thought that someone else is concerned regarding my welfare

14. To have a discussion with my family members about his/her worries

15. To get specifics instructions about recovering the sexual activities of the patient

16. To be able to express fear or worries to my family members

17. To get the information about the prediction of the patient's psychological condition

18. To share my feeling to someone

19. To receive support in regards to financial worries/concerns

20. To get the information about the feeling and emotion that I might experience during the patient's recovery

21. To have access to talk to someone about the feeling of anger or frustration that I might feel

22. To share my fear to someone

23. To get information about the groups or people who can help solve the problems

24. To have a solitude time

25. To be able to leave the patients without feeling worry

26. To understand that other people also experience the same thing, and that what I undergo is natural

27. To talk to other people who experiences a similar case.

28. To get assistance from other people to help take care of some things or do some household chores and/or cooking

29. To be able to offer valuable assistance to the patient.

Untuk mendapat penjelasan secara rinci tentang perawatan

Untuk berharap bahwa saya dan anggota keluarga saya yang sakit akan memiliki kualitas hidup yang tinggi

Untuk mendapat informasi tentang tindakan yang perlu dilakukan dalam kondisi gawat darurat

Untuk mendapat informasi tentang perkiraan kondisi fisik pasien

Untuk mendapat informasi tentang bagaimana menjalani perubahan gaya hidup

Untuk merasa dihormati/dihargai oleh anggota keluarga saya

Untuk mendapat informasi tentang perubahan gaya hidup

Untuk membantu pasien dalam menjalani perubahan gaya hidup

Untuk merasakan bahwa orang lain memperhatikan kesejahteraan saya

Untuk dapat berdiskusi dengan anggota keluarga saya tentang kekhawatirannya

Untuk mendapat petunjuk yang jelas tentang pemulihan aktivitas seksual pasien

Untuk dapat berbicara kepada anggota keluarga saya tentang ketakutan/kekhawatiran saya

Untuk mendapat informasi tentang perkiraan kondisi psikologis pasien

Untuk berbicara kepada seseorang tentang perasaan saya

Untuk menerima bantuan terkait kekhawatiran masalah keuangan

Untuk mendapat informasi tentang perasaan dan emosi yang mungkin akan saya alami selama proses pemulihan pasien

Untuk berbicara kepada seseorang tentang rasa marah dan frustasi yang mungkin akan saya rasakan

Untuk berbicara kepada seseorang tentang rasa takut saya

Untuk mendapat informasi tentang group atau orang lain yang dapat membantu menyelesaikan masalah

Untuk memiliki waktu buat diri saya sendiri

Untuk meninggalkan anggota keluarga tanpa rasa khawatir

Untuk mengetahui bahwa orang lain mengalami hal yang sama dengan yang saya alami dan hal tersebut adalah wajar

Untuk berbicara dengan orang lain yang mengalami hal yang sama seperti saya

Untuk meminta pertolongan orang lain dalam mengurus beberapa hal atau membantu pekerjaan rumah dan/atau memasak

Untuk dapat menawarkan bantuan yang berarti kepada pasien 
Tabel 2. Content Validity Indeks (CVI) Kuesioner Kebutuhan Pendidikan Caregivers

\begin{tabular}{|c|c|c|c|c|c|c|c|c|c|}
\hline No & $\begin{array}{c}\text { Peryataan isi } \\
\text { kuesioner }\end{array}$ & Ahli 1 & Ahli 2 & Ahli 3 & $\begin{array}{c}\text { Ahli } \\
4\end{array}$ & Ahli 5 & Ahli 6 & $\begin{array}{c}\text { Jumlah } \\
\text { Kesepakatan }\end{array}$ & I-CVI \\
\hline 1. & Item 1 & 4 & 4 & 2 & 3 & 2 & 4 & 4 & 0,67 \\
\hline 2. & Item 2 & 4 & 4 & 4 & 4 & 4 & 4 & 6 & 1,00 \\
\hline 3. & Item 3 & 4 & 4 & 4 & 4 & 4 & 4 & 6 & 1,00 \\
\hline 4. & Item 4 & 3 & 3 & 4 & 3 & 2 & 4 & 5 & 0,83 \\
\hline 5. & Item 5 & 4 & 4 & 4 & 4 & 4 & 4 & 6 & 1,00 \\
\hline 6. & Item 6 & 3 & 3 & 4 & 3 & 2 & 4 & 5 & 0,83 \\
\hline 7. & Item 7 & 4 & 4 & 4 & 4 & 4 & 4 & 6 & 1,00 \\
\hline 8. & Item 8 & 1 & 3 & 2 & 4 & 3 & 4 & 4 & 0,67 \\
\hline 9. & Item 9 & 4 & 4 & 4 & 4 & 4 & 4 & 6 & 1,00 \\
\hline 10. & Item 10 & 2 & 3 & 2 & 4 & 4 & 4 & 4 & 0,67 \\
\hline 11. & Item 11 & 1 & 4 & 2 & 4 & 4 & 4 & 4 & 0,67 \\
\hline 12. & Item 12 & 4 & 3 & 4 & 4 & 4 & 4 & 6 & 1,00 \\
\hline 13. & Item 13 & 3 & 3 & 3 & 4 & 4 & 4 & 6 & 1,00 \\
\hline 14. & Item 14 & 4 & 4 & 3 & 4 & 4 & 4 & 6 & 1,00 \\
\hline 15. & Item 15 & 4 & 4 & 4 & 4 & 4 & 4 & 6 & 1,00 \\
\hline 16. & Item 16 & 3 & 4 & 3 & 4 & 4 & 4 & 6 & 1,00 \\
\hline 17. & Item 17 & 3 & 3 & 3 & 3 & 3 & 4 & 6 & 1,00 \\
\hline 18. & Item 18 & 2 & 3 & 4 & 4 & 4 & 4 & 5 & 0,83 \\
\hline 19. & Item 19 & 3 & 3 & 4 & 4 & 4 & 4 & 6 & 1,00 \\
\hline 20. & Item 20 & 3 & 3 & 4 & 4 & 4 & 4 & 6 & 1,00 \\
\hline 21. & Item 21 & 3 & 3 & 4 & 4 & 4 & 4 & 6 & 1,00 \\
\hline 22. & Item 22 & 3 & 3 & 4 & 4 & 4 & 4 & 6 & 1,00 \\
\hline 23. & Item 23 & 4 & 4 & 4 & 4 & 4 & 4 & 6 & 1,00 \\
\hline 24. & Item 24 & 2 & 3 & 3 & 4 & 4 & 4 & 5 & 0,83 \\
\hline 25. & Item 25 & 4 & 4 & 4 & 4 & 4 & 4 & 6 & 1,00 \\
\hline 26. & Item 26 & 2 & 3 & 3 & 4 & 4 & 4 & 5 & 0,83 \\
\hline 27. & Item 27 & 4 & 3 & 4 & 4 & 4 & 4 & 6 & 1,00 \\
\hline 28. & Item 28 & 3 & 4 & 4 & 4 & 4 & 4 & 6 & 1,00 \\
\hline \multirow[t]{3}{*}{29.} & Item 29 & 3 & 4 & 3 & 4 & 4 & 4 & 6 & 1,00 \\
\hline & & & & & & & & Mean I-CVI & 0,93 \\
\hline & & & & & & & & S-CVI/UA & 0,86 \\
\hline \multicolumn{2}{|c|}{ Proporsi Relevansi } & 0,79 & 1,00 & 0,86 & 1,00 & 0,90 & 1,00 & S-CVI/Ave & 0,93 \\
\hline
\end{tabular}

\section{Pembahasan Validasi Konten}

Perhitungan CVI pada penelitian ini mengacu pada teori yang dikemukakan oleh (Polit \& Beck, 2006). Waltz, C.F., Strickland, O.L., \& Lenz (2005) dan Lynn (1986) menambahkan bahwa untuk melakukan validasi konten minimal melibatkan 3 orang ahli (experts).

Sebagai contohnya yaitu pada penelitian yang dilakukan oleh Rahayu \& Fajarini, \& Setiawan (2018) yang melibatkan 3 orang ahli. Bahkan ada juga penelitian yang hanya melibatkan 2 orang ahli dengan hasil CVI yang bagus nilainya yaitu 1,00 (Indrayana, S., \& Fang, 2019). Namun, Lynn merekomendasikan lima atau enam ahli untuk menilai dan memberikan pendapat dengan rasional semakin banyak ahli maka semakin baik hasilnya. Pada penelitian ini mengikuti rekomendasi Lynn (1986) dengan melibatkan 6 orang ahli. Hasil perhitungan nilai per item pernyataan didapatkan data pada no $1,8,10$, dan 11 hasil I-CVI yaitu 0,67. Sedangkan, Lynn (1986) merekomendasikan bahwa nilai I-CVI tidak boleh kurang dari 0,78 dengan melibatkan 6 orang ahli. Sehingga beberapa pertanyaan ini perlu direvisi sesuai dengan masukan para ahli. Sebagai contoh pada pernyataan no 1 yang semula berbunyi "untuk mengetahui fakta tertentu terkait kondisi pasien" berubah 
menjadi "untuk mengetahui kebenaran kondisi pasien secara jelas". Contoh lainnya yaitu saran para ahli pada pernyataan no 10 yang semula berbunyi "untuk mendapat penghargaan dari anggota keluarga" dianggap kurang jelas, sehingga disarankan berubah menjadi "untuk merasa dihormati/dihargai oleh anggota keluarga saya". Setelah dilakukan perhitungan, hasil kesepakatan dari 6 ahli didapatkan hasil mean I-CVI 0,93. Hasil ini dapat diterima dan sesuai dengan teori Waltz, C.F., Strickland, O.L., \& Lenz (2005) bahwa nilai rata-rata persentase kesepakatan minimal 0,90. Sehingga kuesioner ini dapat dinyatakan valid.

Pada instrumen aslinya yang berbahasa Inggris nilai CVI yang dinilai oleh perawat klinis spesialis dan master of cardiopulmoner adalah 0,97 (Moser et al., 1993). Sehingga, jika melihat hasil sebelumnya dan hasil pada penilitian ini tidaklah jauh berbeda. Hasilnya dapat dianggap memuaskan dan dapat diterima.

$$
\text { Perhitungan }
$$

$\mathrm{S}-\mathrm{CVI} / \mathrm{UA}$ didapatkan dari jumlah nilai I-CVI yang lebih dari 0,78 dibagi dengan jumlah pernyataan. Hitungannya adalah sebagai berikut: $(1,00+1,00+0,83+1,00+0,83+1,00+1,0$ $0+1,00+1,00+1,00+1,00+1,00+1,00+0$ $, 83+1,00+$

$1,00+1,00+1,00+1,00+0,83+1,00+0,83$ $+1,00+1,00+1,00) / 29=0,86$.

Sedangkan untuk perhitungan S-CVI/Ave dihitung dari proporsi relevansi item pernyataan yang dinilai 3 atau 4 oleh para ahli dibagi jumlah para ahli. Perhitungannya adalah $(0,79+1,00+0.86+1,00+0,90+1$, 00) $/ 6=0,93$. Menurut teori Polit \& Beck (2006) hasil S-CVI/Ave dengan mean I-CVI, nilainya akan sama. Jadi dapat disimpulkan bahwa ada kesamaan hasil dari perhitungan secara horisontal dan vertikal.

Pada hasil didapatkan hasil juga tentang keakuratan, kejelasan, dan kemudahan dipahami. Konsep ini didapatkan dari penelitian sebelumnya yang dilakukan oleh (Yaghmale, 2003). Penilaian yang digunakan untuk menilai tersebut menggunakan 4 skala Likert. Hal ini sama dengan yang dilakukan dalam penghitungan relevansi (Polit \& Beck, 2006).

Setelah proses penerjemahan dan validasi konten, kemudian kuesioner disesuaikan dengan perubahan dan dilakukan proofreading untuk memperbaiki tata bahasa. Pada akhirnya, kuesioner dikirimkan kembali ke penciptanya lengkap dengan versi Bahasa Indonesia dan versi Bahasa Inggrisnya.

\section{KESIMPULAN}

Kesimpulan yang didapat dari penelitian ini adalah pertama, terciptanya kuesioner "Educational Needs of Caregivers Instrument" ke dalam versi Bahasa Indonesia yang diberi nama "Kuesioner Kebutuhan Pendidikan Caregivers". Kedua yaitu kuesioner ini dinyatakan valid melalui perhitungan validasi konten.

Hasil penelitian ini diharapkan dapat diteruskan untuk penelitian selanjutnya yaitu pada populasi Caregivers keluarga dari pasien dengan gagal jantung. Selain itu, juga diharapkan kuesioner ini dapat dipergunakan oleh peneliti lainnya.

\section{UCAPAN TERIMAKASIH}

Peneliti mengucapkan banyak terimakasih kepada National Cheng 
Kung University (NCKU) yang telah membuka wawasan pengetahuan, Pencipta kuesioner yaitu Debra K. Moser, PhD, RN, FAAN yang sangat responsif menanggapi terkait kuesioner, para ahli yang terlibat dalam memberikan pendapat dan penilaian terhadap kuesioner, para senior dan teman-teman satu alumni
NCKU yang banyak memberikan masukan, dan STIKes Jayakarta yang memberikan support system terutama yang terhormat Bapak dr. Ahmad Harjadi, M.Sc., serta pihak-pihak yang sangat berjasa yang tidak dapat peneliti sebutkan satu persatu.

\section{DAFTAR PUSTAKA}

Anggreani, R., Mahama, C. N., Durry, M. F., Mawuntu, A. H. P., Th, M., \& Kembuan, M. A. H. N. (2019). Penerjemahan dan Validasi Linguistik Rapid Eye Movement Sleep Behavior Disorder Screening Questionnaire (RBDSQ) Kebahasa Indonesia di Manado, Indonesia: Penelitian Permulaan, 2(2), 20-29.

Chen, H. M., \& Clark, A. P. (2007). Sleep disturbances in people living with heart failure. Journal of Cardiovascular Nursing, 22(3), 177-185.

Chen, H. M., Clark, A. P., Tsai, L. M., \& Chao, Y. F. C. (2009). Self-reported sleep disturbance of patients with heart failure in Taiwan. Nursing Research, 58(1), 63-71.

Collins, L., \& K Swartz. (2011). Caregiver care. American Family Physician, $1309 . \quad$ Retrieved from https://pdfs.semanticscholar.org/e43d/2b346b994f0043e46a2158f356bac6 952466.pdf

Delphi, M., \& Rating, M. F. (2014). Seminar Nasional IENACO 2014 ISSN: 2337-4349, (1970), 474-483.

Etemadifar, S., Shahriari, M., Farsani, A., \& Bahrami, M. (2014). Informational needs and related problems of family caregivers of heart failure patients: A qualitative study. Journal of Education and Health Promotion, 3(1), 113.

Hwang, B. B., Fleischmann, K. E., Howie-, J., Stotts, N. A., Dracup, K., \& Hour, C. E. (2011). Caregiving for patients with heart failure: impact on patients' families. American Journal of Critical Care, 20(6), 431-442.

Indrayana, S., \& Fang, S. Y. (2019). Validitas dan reliabilitas The Brief Illness Perception Questionnaire versi Bahasa Indonesia pada Pasien Diabetes Mellitus. Dinamika Kesehatan Jurnal Kebidanan Dan Keperawatan, 10(1) 
KBBI. (2019). Kuesioner. Retrieved from https://kbbi.web.id/kuesioner. Diakses pada tanggal 10 Oktober 2019

KBBI. (2019). Pengertian Instrumen. Retrieved from https://kbbi.web.id/instrumen. Diakses pada tanggal 10 Oktober 2019

Lynn, M. R. (1986). Determination and quantification of content validity. Nursing Research, 35(6), 382-385.

Moser, D. K., Dracup, K. A., \& Marsden, C. (1993). Needs of Recovering Cardiac Patients and Their Spouses - Compared Views. International Journal of Nursing Studies, 30(2), 105-114.

Muhammad, N. N., Shatri, H., Djoerban, Z., \& Abdullah, M. (2017). Uji Kesahihan dan Keandalan Kuesioner World Health Organization Quality of Life-HIV Bref dalam Bahasa Indonesia untuk Mengukur Kualitas Hidup Pasien HIV/AIDS. Jurnal Penyakit Dalam Indonesia, 4(3), 112.

National Alliance for Caregiving. (2015). Caregiving in the U.S.- AARP 2015 Report. Bethesda, Md: National Alliance for Caregiving; 2015. Retrieved from https://www.aarp.org/content/dam/aarp/ppi/2015/caregiving-in-theunited-states-2015-report-revised.pdf. Diakses pada tanggal 7 Agustus 2019

Polit, D. F., \& Beck, C. T. (2006). The content validity index: Are you sure you know what's being reported? Critique and recommendations. Research in Nursing and Health, 29(5), 489-497. https://doi.org/10.1002/nur.20147

Pulignano, G., Del Sindaco, D., Minardi, G., Tarantini, L., Cioffi, G., Bernardi, L., ... Giovannini, E. (2010). Translation and validation of the Italian version of the European heart failure self-care behaviour scale. Journal of Cardiovascular Medicine, 11(7), 493-498. https://doi.org/10.2459/JCM.0b013e328335fbf5

Rahayu, S. (2017). 印尼心藏衰竭病人之家屬照顧者的衛教需求. 成功大學護 理 學 系 學 位 論 文 , 1-77. Retrieved from http://www.airitilibrary.com/Publication/alDetailedMesh?docid=U00260802201717114900

Rahayu, S., Fajarini, M., \& Setiawan, A. (2018). Content validity of Evidence Based Practice Questionnaire (EBPQ). In The 2nd International Nursing Scholars Congress, Universitas Indonesia (p. 67).

Soares, L. S., De Paula, J. J., Malloy-Diniz, L. F., De Miranda, D. M., \& Costa, D. D. S. (2017). Translation, cultural adaptation, and content validity 
index of the Juvenile Love Scale to the Brazilian context. Revista de Psiquiatria Clinica, 44(3), 63-66.

Sousa, V. D., \& Rojjanasrirat, W. (2011). Translation, adaptation and validation of instruments or scales for use in cross-cultural health care research: A clear and user-friendly guideline. Journal of Evaluation in Clinical Practice, 17(2), 268-274.

Swartz, K., \& Collins, L. G. (2019). Caregiver Care. American Family Physician, 99(11).

Tsai, P. K., Wang, R. H., Lee, C. S., Tsai, L. M., \& Chen, H. M. (2015). Determinants of self-care decision-making in hospitalised patients with heart failure. Journal of Clinical Nursing, 24(7-8), 1101-1111.

Walden, J. a, Dracup, K., Westlake, C., Erickson, V., Hamilton, M. a, \& Fonarow, G. C. (2001). Educational needs of patients with advanced heart failure and their caregivers. The Journal of Heart and Lung Transplantation: The Official Publication of the International Society for Heart Transplantation, 20(7), 766-769.

Waltz, C.F., Strickland, O.L., \& Lenz, E. R. (2005). Measurement in nursing and health research ( $3 r d$ ed.). New York: Springer Publishing Co.

World Health Organization. (2016). Process of translation and adaptation of instruments.

http://www.who.int/substance_abuse/research_tools/translation/en/

Yaghmale, F. (2003). Content validity and its estimation. Journal of Medical Education, 3(1), 25-27. 